of scientific books was stressed. The third section of the congress was devoted to general cultural talks, and the subjects dealt with in this section mainly comprised the history of science in the Arab nations, such as progress in mathematical and navigational sciences, by Kazwini, Ibn E1 Haytham, Khowarizmi, El Tousy, El Bayrouni, El Battani, Ibn Sena, Gaber Ibn Hayan and others.

During the congress, exhibitions were arranged: one dealing with modern materials organized by the United Nations Educational, Scientific and Cultural Organization, another with the history of science in the Arab nations, and a third with scientific books written in Arabic and other languages. The congress also arranged for visits to places of scientific interest, such as the Institute of Marine Biology at Alexandria, the Roman Museum, the Misr Company for Cotton Weaving, the Misr Company for Artificial Silk, and the Burg el Arab field for desert plants. Among the decisions made in the final meeting of the congress was a recommendation for the institution of an Arab Scientific Union to be initiated by the Arab Union Organization.

\section{WATER POLLUTION RESEARCH}

\section{REPORT FOR 1952}

$\mathrm{T}$ HE report of the Director of Water Pollution Research and that of the Water Pollution Research Board are contained in an interesting publication entitled "Water Pollution Research 1952"*. It is not possible in a short notice to indicate all the interesting work that is being done on this important subject, and the reports themselves should be consulted.

Work has continued on the effect of various substances on the disinfecting action of chlorine on bacteria in water, and methods have been improved for the enumeration of Streptococcus faecalis, an organism which is one of the indicators of fæcal pollution. Work has also been done on the removal of radioactive jodine discharged as a constituent of sewage in small amounts into streams after its use in medicine.

Work on sewage at Birmingham has confirmed that slow rotation of percolating filters lowers the biochemical oxygen demand of the effluent and considerably increases its nitrification. Other work on sewage has shown that a volume of filtering medium of 10 cubic yards for each $10-20$ persons gives effluents of very good quality. Experiments done in co-operation with the Gas Board have shown that spent liquor from the gasworks at Hinckley can be treated in a percolating filter in admixture with sewage, in a concentration up to 3 per cent, by volume, without causing much deterioration of the quality of the effluent. This proportion is very much higher than that possible when gas liquor of the ordinary type is used. The methods used at Hinckley for the treatment of hot gas by electrostatic precipitation, with the object of reducing the concentration of higher tar acids in the liquor, are described. Further work on this subject is in hand.

Work has also been done on industrial waste waters. In the treatment of black liquor resulting

*Department of Scientific and Industrial Research. Report of the Water Pollution Research Board, with the Report of the Director of Water Pollution Research for the Year 1952 . Pp. iv $+64+4$ plates. (London: H.M.S.O., 1953.) 2s, 6d. net. from the kiering of cotton, an active sludge has been developed which, when it is mixed with the neutralized liquor, causes rapid anaerobic fermentation with the evolution of gas containing about 80 per cent of methane. Experiments have also been done on methods of treating simple and complex metallic cyanides mixed with sewage. It has proved possible to obtain, from sewage containing potassium, zinc and cadmium cyanides in concentrations equivalent to a hundred parts of hydrogen cyanide per million, effluents which contained an average of less than $0 \cdot 2$ p.p.m. of cyanide. It has also been shown that the toxicity of potassium cyanide in small concentrations increases markedly as the concentration of oxygen in solution is reduced. This is important in the design of toxicity tests and in the effect on fish of toxic substances in rivers.

The largest section of the report discusses the work on the Thames Estuary. Among the subjects studied are the distribution of salt and fresh water, the effect of rough weather in raising the level of oxygen dissolved in the water, pollution by discharges of organic matter contained in streams, sewage effluents and industrial wastes, the particle size of deposits in the Estuary, the important effect of suspended solids on the biochemical oxygen demand of Estuary water, the inhibition by oxygen of bacterial reduction of sulphate to sulphide and the catalytic effect of mud in promoting oxidation of sulphide by oxygen in solution.

The presence of large quantities of foam in rivers has been reported from many places during the year, and work on this problem is contemplated. With regard to the problem of pollution of beaches by oil, investigations on methods of preventing this pollution, in which a number of oil companies are cooperating, is in progress. A special problem, not specifically mentioned in these reports, would seem to be the general effects of substances now being extensively used for the control of pests of crops. Since the end of 1952 Water Pollution Abstracts, published by H.M. Stationery Office, has issued 35,000 abstracts, and the size of this monthly publication was increased in 1953 to meet the large number of papers now being written in Britain and elsewhere on this subject.

\section{THE COSMOTRON AT THE BROOKHAVEN NATIONAL LABORATORY}

\section{$\mathrm{V}$}

ALUABLE information concerning nuclear forces and the properties of fundamental particles can be obtained from the study of the interaction of high-speed nucleons with nuclear matter and from the interaction of individual nucleons. The energies required for the production of the lighter $\pi$-mesons and the heavier mesons are known from cosmic-ray investigations, and it has been the endeavour of many workers to produce such mesons in the laboratory by means of particle accelerators. Already during 1946-47 several particle accelerators capable of producing particles with energies of $300-400 \mathrm{MeV}$., sufficient for $\pi$-mesons, were under construction; but the design of accelerators for production of the heavier mesons requiring energies of the order of $5,000 \mathrm{MeV}$. had not been investigated. 